\title{
Article
}

\section{The role of emotional resilience, childhood parentification, and attachment style on antisocial behaviour in adulthood: a comparison of an offender and normative population}

McGauran, Andra, Brooks, Matthew and Khan, Roxanne

Available at http://clok.uclan.ac.uk/26155/

McGauran, Andra, Brooks, Matthew and Khan, Roxanne ORCID: 0000-00023485-2450 (2019) The role of emotional resilience, childhood parentification, and attachment style on antisocial behaviour in adulthood: a comparison of an offender and normative population. Journal of Criminal Psychology, 9 (2). pp. 75-87. ISSN 2009-3829

It is advisable to refer to the publisher's version if you intend to cite from the work. http://dx.doi.org/10.1108/JCP-08-2018-0035

For more information about UCLan's research in this area go to

http://www.uclan.ac.uk/researchgroups/ and search for <name of research Group>.

For information about Research generally at UCLan please go to http://www.uclan.ac.uk/research/

All outputs in CLoK are protected by Intellectual Property Rights law, including Copyright law. Copyright, IPR and Moral Rights for the works on this site are retained by the individual authors and/or other copyright owners. Terms and conditions for use of this material are defined in the policies page. 
Citation: McGauran, A., Brooks, M. \& Khan, R. (2019). The role of emotional resilience, childhood parentification, and attachment style on antisocial behavior in adulthood: A comparison of an offender and normative population. Journal of Criminal Psychology. doi:10.1108/JCP-08-2018-0035

The role of emotional resilience, childhood parentification, and attachment style on antisocial behavior in adulthood: A comparison of an offender and normative population

\author{
Andra McGauran* \\ National Probation Service, 41 West Road, Lancaster, UK \\ Matthew Brooks \\ Manchester Metropolitan University, Department of Psychology, UK \\ Roxanne Khan \\ University of Central Lancashire, School of Psychology, UK
}

*Correspondence concerning this article should be addressed to:

Andra McGauran

National Probation Service

41 West Road

Lancaster

LA1 UK

E-mail: Andra.mcgauran @ probation.gsi.gov.uk 


\begin{abstract}
Purpose: Despite a robust link between poor caregiver attachment and antisociality, few studies have examined the influence of parentification and emotional resilience on delinquency in later life, in groups at differing risk for antisocial conduct.

Methodology: This pilot study compared the influence of parentification, attachment style (avoidant or anxious) and emotional resilience on adulthood antisocial behaviour in an offender and normative sample. Of the 137 participants in this study, 66 were supervised by the National Probation Service (age $M=36.90, S D=13.91$ ), and 71 were recruited from community-dwelling and student populations (age $M=31.83, S D=13.25$ ).
\end{abstract}

Findings: In partial support of the predictions, participants in the offender group reported significantly greater levels of attachment anxiety compared to the normative group. However, emotional resilience was positively associated with antisociality in the normative sample. Research implications: This small-scale investigation indicates value in exploring these specific variables in a larger, matched samples study, to enable clearer comparisons to be made between offender and normative groups.

Practical implications: The preliminary findings suggest that attachment anxiety is associated with antisociality in offender populations, which indicate a therapeutic focus on attachment anxiety as part of correctional care and offender rehabilitation.

Originality: This study is novel in its aim to examine the influence of childhood parentification, attachment deficits and emotional resilience on adulthood antisociality in participants from a high-risk offender sample and non-high-risk normative sample.

Keywords: Anxious attachment, avoidant attachment, delinquency, parentification 


\section{Introduction}

The pathway to adulthood criminality is arguably rooted in an individual's childhood. A substantial body of work offers some explanations as to how and why people's antisocial behaviour stems from their early familial experiences (Farrington, 2003; Fox, Perez, Cass, Baglivio \& Epps, 2015). When compared with normative populations, for example, offender groups report nearly four times more adverse childhood experiences (including problematic relationships and an absence of affection) that are strongly associated with antisocial behaviour in later life (Reavis, Looman, Franco, \& Rojas, 2013). Yet, even in studies of people not at high-risk of offending, multiple types of adverse childhood experiences (including household dysfunction and neglect) are associated with an elevated risk for a range of antisocial conduct, including delinquent behaviours, bullying, fighting, and weaponcarrying (Duke, Pettingell, McMorris, \& Borowsky, 2010). These findings indicate multiple risk factors associated with negative parenting styles in childhood that may contribute to adulthood antisocial conduct, in both offender and normative populations. These include poor attachment and parentification - a family process in which children or adolescents assume adult responsibilities and/or parental roles that may be developmentally inappropriate (Boszormenyi-Nagy \& Spark, 1973). The influence of emotional resilience as a protective factor has also been emphasised, as this may mitigate the risk posed by detrimental childhood experiences on antisociality (Leitch, 2017; Lösel \& Farrington, 2012). The extent to which these factors individually or collectively explain antisocial conduct in offender and normative samples has not yet been explored in a single study. Furthermore, studies of attachment, emotional resilience and parentification could help inform risk assessment and management of offenders who present with such characteristics in the criminal justice system, forming the rationale for this pilot investigation. 


\section{Avoidant or anxious attachment styles}

The importance of a healthy infant-caregiver attachment is well-documented. Attachment theory (Bowlby, 1969) provides a useful framework to consider the potential negative and positive impacts that arise in the aftermath of poor childhood attachments. In his theory, Bowlby (1969) proposes that an infant's relationship to their primary caregiver is critical to current and future functioning, serving as a prototype for subsequent social relationships. Indeed, studies have shown that children who experience secure attachments develop confidence, emotional security and positive interpersonal skills, fostering the ability to empathize with others and appropriately manage stress (Marshall, 2010; Savage, 2014). Likewise, poor attachments in infancy may increase a child's anxiety, leading to distrust of others and impulsive, aggressive reactions to stressful situations.

Children with poor caregiver attachments are more likely to form problematic personal and social relationships, develop maladaptive coping mechanisms, and engage in antisocial acts as an adult (Sigre-Leirós, Carvalho, \& Nobre, 2016). There is robust support for the link between poor childhood attachments and delinquency in later life from large scale meta-analyses and comprehensive reviews (e.g., Groh, Fearon, van IJzendoorn, BakermansKranenburg, \& Roisman, 2017; Hoeve et al., 2009, 2012; Savage, 2014). More specifically, empirical studies report the anxious and avoidant dimensions of attachment as more strongly associated with antisocial behaviour in both normative samples (Arbona \& Power, 2003) and prison populations (Hansen, Waage, Eid, Johnsen, \& Hart, 2011) when compared with their securely attached counterparts. Anxious attachment is defined as the extent to which individuals struggle with feelings of abandonment and fear of rejection, while avoidant attachment relates to how comfortable an individual is being close to others (Fraley et al., 2000). Anxious and/or avoidant attachment styles have been strongly linked with aggressive 
and violent behaviour, with offenders found to report more avoidant attachment and attachment anxiety compared to the general population (Ogilvie, Newman, Todd \& Peck, 2014). Offenders with attachment anxiety struggle with intimacy and trusting others. They are often found to externalise their emotions through aggression and substance abuse (Hansen, Waage, Johnson, \& Hart, 2011). Conversely, those with anxious attachment fear rejection; they may 'cling' to their partners and exhibit aggressive behaviour when they predict abandonment (Hansen et al., 2011). Collectively, these anxious-avoidant attachment styles can create deficits in empathy, trust and a lack of connectedness with others, which can lead to a proclivity to engage in antisocial conduct (Bowlby, 1969; Groh et al., 2017). Parentification may be one element of negative parenting styles associated with distorted attachment that could further explain antisocial conduct.

\section{Parentification}

Parentification occurs when a child takes a parental role due to the parent's inability to care effectively for their children (Chase, 1999). This may be an instrumental role (e.g., the physical care of a family member) or an emotional role (e.g., responsibility for a family member's emotional well-being; Barnett \& Parker, 1998). Parentification may interfere with the emotional development of the child, skewing their sense of identity and role within the family (Jurkovic, Morrell, \& Thirkield, 1999). This has been associated with emotional internalising (e.g., manifesting as depression) and externalising symptoms (e.g., displays of aggression; Hooper, Marotta, \& Lanthier, 2008; Van Loon, Van De Ven, Van Doesum, Hosman, \& Witteman, 2015). Childhood parentification is also linked with maladjustment in later life, including the development of adulthood psychopathology in response to a neglectful and unpredictable family environment (Hooper, DeCoster, White, \& Voltz, 2011; Hooper et al., 2008), although few studies have considered parentification in relation to 
antisocial behaviour. These findings align with Attachment Theory (Bowlby, 1969), which states that consistent and structured familial boundaries encourage positive development. Parentification distorts these boundaries when children take on inappropriate adult roles, thereby negatively affecting their emotional well-being (Van Loon et al., 2015). However, parentification might not always be negative (Garber, 2011). In economically-deprived families, for example, parentification (when mediated by the influence of family strength) was found to be negatively correlated with delinquent conduct (Nurwianti, Poerwandari, \& Ginanjar, 2018). It has also been suggested that parentified children may have greater psychological resilience and more secure attachment styles during adulthood, as a result of being adaptive and responsible in childhood (Hooper et al., 2008). The disparity of these findings indicate scope for studies to compare adults at high-risk and non-high-risk for antisocial behaviour. There is a need to explore differences in the influence of childhood parentification and adulthood attachment style in addition to emotional resilience, given the potential for resilience to act as 'buffer' against the negative influences of parentification.

\section{Emotional resilience}

Emotional resilience, the ability to overcome significant adversity despite challenging circumstances, may act as a protective factor from detrimental childhood experiences and consequent adult antisocial conduct (Masten, Best, \& Garmezy, 1990; Wagnild, 2009). It has been proposed that resilience may explain why many mistreated children lead law abiding lifestyles in adulthood (Zemel, Ronel, \& Einat, 2016). Resilient people tend to be positive, calm, have good social skills, happier relationships and the ability to 'bounce back' from stress with little difficulty (Amat, Subhan, Jaafar, Mahmud, \& Johari, 2014). Studies report that resilience can act as a protective factor against involvement in crime or desistance from antisocial behaviour (Arslan, 2016; McKinight, \& Loper, 2002; Zemel et al., 2016), and that 
resilience in children is a protective factor in preventing delinquent behaviour in adulthood (Campbell-Sills, Cohen, \& Stein, 2006). Despite these findings, few studies have explored whether the relationship between emotional resilience and engagement in antisocial behaviour differs among offender and normative populations.

\section{Research aims}

This pilot study compared the influence of childhood parentification, adulthood attachment style (avoidant or anxious), and emotional resilience on antisocial behaviour in two adult samples. The first sample comprised a high-risk for antisociality group of offenders recruited from the UK National Probation Service $(N=66)$. The second sample were a nonhigh-risk normative sample recruited from community-dwelling and student populations $(N=$ 71). As previous research findings have been mixed, while it was predicted that there will be difference in experiences of anxious attachment, avoidant attachment, and parentification for participants in the offender group and the normative group, the direction of these differences were not postulated. It was further predicted that these experiences would predict their engagement in antisocial behaviour. It was further hypothesised that emotional resilience would negatively predict antisocial behaviour and that the normative group would report higher levels of emotional resilience than offenders.

\section{Method}

\section{Participants and procedure}

The offender sample were 66 White British adults $(M$ age $=36.90, S D=13.91)$ under the supervision of the National Probation Service (NPS) ${ }^{[1]}$. The majority of participants were male (92\%); this sex imbalance reflects the offending population within NPS sample at the time of these interviews, who were randomly selected from the case-load of staff members 
working at a probation office in northwest England. These participants were 'MAPPA' (Multi-Agency Public Protection Arrangements) ${ }^{[2]}$ offenders due to either their high risk status, the nature of their offence and subsequent sentence (i.e. being sentenced to 12 months or more custody for a sexual or violent offence), or high risk offenders as they were all being supervised by the NPS. Offender participants completed the questionnaires at probation premises. It was confirmed to all offender participants that only those directly involved in the research would have access to their responses, although any disclosures concerning harm to themselves or to others that was not previously known would be shared with the appropriate authorities.

The normative sample were 71 majority White British adult $(M$ age $=31.83, S D=$ 13.25) females (69\%) who were either students or in full-time employment. No other demographic measures were taken from either sample. Participants in this group were recruited via opportunity sampling from classes and public areas in a large university in the northwest of England. Recruitment via snowballing methods was also used to reach potential participants in the local community (e.g., inside shopping centres and in places of work).

The study was given full approval by the institutional ethics committee, in accordance with the British Psychological Society (BPS) guidelines. Once all participants gave informed consent, they were provided with a questionnaire booklet (placed within a detailed briefing and debriefing sheet) to complete alone. Participants in the offender group were offered support, from the first author, to complete the questionnaire. For both samples, there were no exclusion criteria adopted prior to their participation; however, all but one participant from the offender sample requested this support and asked for questions to be read aloud due to reading difficulties. All participants were volunteers and no incentives were offered for taking part in the study. 


\section{Measures}

Anxious and avoidant attachment. The Experiences in Close Relationships Questionnaire-Revised (ECR-R; Fraley, Waller, \& Brennan, 2000) is a 36-item questionnaire which assesses anxious and avoidant attachment within interpersonal relationships. Each item is measured on a seven-point scale, ranging from 'significantly disagree' (1) to 'significantly agree' (7). Of the 36 items, 18 measure anxious attachment, such as "I am afraid I will lose my partner's love", and 18 measure avoidant attachment, for example, "I prefer not to be close to romantic partners". Higher scores reflect greater anxious and/or avoidant attachment. The ECR-R has demonstrated high internal consistency $(>.90)$ for both anxious and avoidant dimensions (Fraley et al., 2000), and suitable convergent and discriminant validity (Sibley, Fischer, $\&$ Liu, 2005). In the current study, the anxious attachment $(\alpha=.89)$ and avoidant attachment $(\alpha=.72)$ subscales demonstrated good and acceptable internal consistency, respectively.

Parentification. The Parentification Questionnaire (PQ; Jurkovic \& Thirkield, 1998) is a 44-item questionnaire that measured participants' experiences of parentification. This included statements pertaining to the individuals' childhood experiences of taking on an adult role within the family, both emotionally and practically. Each item is measured by answering 'True' (1) or 'False' (2) to each statement, for example, "I was frequently responsible for the physical care of some member of my family", "my parents rarely turned to me for help" and "when someone in my family was upset, I would almost always become involved in some way". The questions related to individuals' experiences within childhood, prior to the age of eighteen. Higher scores denoted the increased levels of parentification experiences as a child. Hooper and Wallace (2010) report that the PQ holds good internal consistency, moderate to high correlations among items, and good predictive validity with measures of somatisation, 
depression and anxiety in expected theoretical directions. Internal consistency was good in the current study $(\alpha=.83)$.

Emotional resilience. The Brief Resilience Scale (BRS; Smith, Dalen, Wiggins, Tooley \& Bernard, 2008) is a six-item measure of a person's ability to 'bounce back' from hardship. Each item is measured using a five-point scale from 'significantly disagree' (1) to 'significantly agree' (5), with items such as "It is hard for me to snap back after hard times". Higher scores indicated lower levels of emotional resilience. The BRS has demonstrated good internal consistency across studies (e.g. Amat et al., 2014; Smith et al., 2008) and discriminant predictive validity with other psychological outcomes such as optimism and perceived stress (Smith et al., 2008). Internal consistency in the current study was good ( $\alpha=$ $.87)$.

Antisocial behaviour. The Antisocial Behaviour Questionnaire (ABQ; Khan \& Cooke, 2008) is a 10-item measure of an individuals' participation in antisocial behaviour after the age of 18 only. It was previously used in studies of non-custodial offender populations where it has demonstrated good internal consistency, and positive correlations with measures of antisocial behaviour in school and general aggression (Brooks \& Khan, 2015). Example items include "Have you ever taken any illegal substances?" and "Broke into another person's home/property (for fun or theft)" rated on a five-point scale from 'never' (1) to 'always' (5). Answers are summed with higher scores indicative of more antisocial tendencies. In the current study, the measure demonstrated good internal inconsistency $(\alpha=$ .86).

\section{Data analysis}

Differences between the two (offender and normative) groups were calculated using independent samples t-tests. The direction and magnitude of relationships between variables 
were assessed using bivariate Pearson's correlations. Multiple regression analyses were conducted to assess predictors of antisocial behaviour in both samples.

\section{Results}

\section{Differences between offender and normative groups}

The distribution of all 10 antisocial behaviours measured using the ABQ for the offender sample and the normative sample are presented in Table 1. It is noteworthy that with the exception of intentionally provoking a physical fight with another person, a majority of both groups reported never or only once engaging in nine of the ten antisocial acts. Only one antisocial act, consuming alcohol before the age of 18 , was reported by the majority of both the offender sample and normative sample (89\% and $73 \%$ respectively).

Insert Table 1 about here

Means and standard deviations for both (offender and normative) groups are reported in Table 2. To test the hypothesis that participants in the offender sample would report significantly more experiences of anxious attachment, avoidant attachment, and parentification but lower levels of emotional resilience compared to the normative sample, independent t-tests were conducted. As expected, this showed that offenders reported significantly more involvement in antisocial behaviour $[t(87.13)=6.43, p<.001, d=1.11]$, as well as greater anxious attachment than the normative group $[t(124.16)=3.36, p=.001, d$ $=0.57]$. Contrary to predictions, however, no significant differences were found between the two groups for avoidant attachment $[t(128.16)=-1.08, p=.282, d=0.19]$, parentification $[t$ 
$(134.98)=1.22, p=.223, d=0.21]$ or emotional resilience $[t(98.79)=1.70, p=.093, d=$ $0.30]$.

Insert Table 2 about here

\section{Antisocial behaviour in the offender sample}

Bivariate correlations were conducted to explore the direction and magnitude of relationships between each of the key variables in the offender sample. The correlations between each variable are presented in Table 3. The only significant relationship found was a negative correlation between anxious attachment and emotional resilience.

Insert Table 3 about here

To test the hypothesis that poor attachment, parentification and emotional resilience are associated with offending behaviour among adult offenders, a hierarchical regression analysis was conducted. As age and gender have long been shown to exert influence on antisociality (Farrington \& Painter, 2004; Farrington, 1995), these were entered as controls in Step 1 of the regression, with psychological variables entered in Step 2. The results are presented in Table 4. There were no concerns over multicollinearity (VIF values $\leq 1.20$; Tolerance values $\geq .84)$. The hierarchical regression results indicated that at Step 1, age and gender contributed significantly to the model $[F(2,61)=12.55, p<.001]$ and accounted for $26.8 \%$ of the variance in antisocial behaviour among the offending group. Age was a negative predictor of antisocial behaviour $(p<.001)$. The psychological variables introduced in Step 2 
produced a significant model $[F(6,57)=4.04, p=.005]$, although they explained an additional $1 \%$ of the variance in antisocial behaviour, which did not represent a significant change $\left[F_{\text {change }}(4,57)=.14, p=.966\right]$. The overall variance in the Step 2 model accounted for by the predictors showed a reduction to $22.5 \%$. While age remained a significant negative predictor of antisocial behaviour $(p<.001)$, none of the psychological variables were significantly related to antisocial behaviour within the offender sample.

Insert Table 4 about here

\section{Antisocial behaviour in the normative sample}

The correlations between each of the variables within the normative group are presented in Table 3. Significant positive correlations were found between attachment anxiety and parentification, and emotional resilience and antisocial behaviour. Significant negative correlations were found between attachment anxiety and emotional resilience and emotional resilience and parentification.

Hierarchical regression analysis was conducted to assess anxious attachment, avoidant attachment, parentification and emotional resilience as predictors of antisocial behaviour in this normative sample. Like the offender sample, age and gender were entered as controls in Step 1 of the regression, with psychological variables entered in Step 2 (see Table 4). There were no concerns over multicollinearity (VIF values $\leq 1.24$; Tolerance values $\geq .80$ ). The inclusion of age and gender in Step 1 of the regression did not produce a significant model $[F$ $(2,62)=2.82, p=.067]$, and accounted for $5.4 \%$ of the variance in antisocial behaviour among the normative group. Males were significantly more likely to report antisocial 
behaviour compared to females $(p=.021)$. The psychological variables introduced in Step 2 produced a significant model $[F(6,58)=3.46, p=.005]$, and accounted for an additional $18 \%$ of the variance in antisocial behaviour, which represented a significant change upon the previous step $\left[F_{\text {change }}(4,58)=3.54, p=.012\right]$. The Step 2 model therefore accounted for $18.7 \%$ of the variance in antisocial behaviour among the normative group. In this model, emotional resilience emerged as the only significant variable that was (positively) related to antisocial behaviour $(p=.001)$, and gender was no longer significant.

\section{Discussion}

This pilot study compared participants from a high-risk offender sample with a nonhigh-risk normative sample to explore whether differences in childhood parentification, attachment, and emotional resilience explained their adulthood antisocial conduct. Some differences were found between the two groups, providing partial support for the study's hypotheses. As expected, the offender group reported higher levels of attachment anxiety and antisocial behaviour compared to the normative group. Furthermore, age was a negative predictor of antisocial behaviour in offender group only. Together, these findings support past research linking poor attachments and lower age with increased risk of criminality (Farrington, 1995; Groh et al., 2012; Hoeve et al., 2012).

\section{Similarities across normative and offender groups}

Contrary to expectations, there were no significant differences between the two groups in relation to parentification, avoidant attachment or emotional resilience, as reported in previous studies (e.g., Arslan, 2016; Groh et al., 2012; Hooper et al., 2011). These factors were not found to be associated with antisocial behaviour in the two groups. Given that parentification is reported to have positive outcomes in certain circumstances (cf. Hooper et al., 2008; Nurwianti, et al., 2018), it may be that the parentification measure was not sensitive 
enough to distinguish destructive parentification from so-called "healthy parentification" (Garber, 2011). The current study did not measure perceptions of parentification, which some research has found to be relevant in explaining the likelihood of antisocial outcomes (Jankowski, Hooper, Sandage, \& Hannah, 2013). In this regard, parentification may in fact be advantageous for individuals who view their parentification experiences as fair. This may be further compounded if individuals in the two samples have normalised their parentification experiences, rather than perceiving them as dysfunctional. Thus, parentification may be a less relevant factor in explaining antisocial conduct in these circumstances.

Means and SD scores for avoidant attachment were similar for the offender and nonoffender groups and did not explain antisocial conduct. Existing research (e.g. Groh et al, 2017) has tended to focus on attachment in youth, rather than among adult samples. However, one review of 74 studies (Hoeve et al., 2012) indicated that the relationship between poor attachments and delinquency weakens as people age and mature, which may explain why avoidant attachment exerted minimal influence on antisocial behaviour. Furthermore, the avoidance of attachments can be characterised as a self-protective mechanism that involves denial and externalising blame as typical coping strategies (Hansen et al., 2011). Maintaining a positive model of the self could buffer against perceptions of emotional vulnerability, which may have been a concern for individuals in the two groups, regardless of the level of antisocial behaviour reported.

Similarly, the finding that emotional resilience was not a protective factor against antisocial behaviour in this study was contrary to expectations, as was the positive correlation between emotional resilience and antisocial behaviour in the normative sample. While it was predicted that these participants would score significantly lower than offenders in each of the 10 antisocial acts measured, those who reported higher levels of resilience also reported 
engaging in more antisocial activity. As previous research links low levels of resilience with antisocial behaviour (e.g., Armstrong et al., 2005; McKnight \& Loper, 2002), this result was surprising. However, prior research involving offenders (e.g., Brooks \& Khan, 2015) has found that they tend to exaggerate personal abilities in response to self-report measures. Resilience has been described as an "internal resource" (Wagnild, 2009, p. 108) which connotes perceptions of optimism, competency, adaptability and inner strength. The nature of the resilience reported in the current study may reflect a distorted perception or defensive quality in that the offending sample may view themselves has having little difficulty in responding to hardship.

\section{Limitations and future studies}

It is noteworthy that a number of methodological factors most likely influenced the unexpected non-significant results in this study. The limitations of retrospective data should also be taken into account, as the passage of time may have contributed to both groups misreporting their childhood experiences and antisocial conduct (Hollin, 1990). Furthermore, due to identification with delinquent peers and attitudes supportive of criminality, participants in the offender group may have felt more at ease than those in the normative group in reporting their antisocial conduct. However, disclosing adverse childhood experiences and emotional issues may have been more difficult for offenders due to perceived emotional vulnerability, and thus minimised (Levenson, Willis, \& Vicencio, 2017).

Screening measures were not used to assess prior criminal history (in the normative sample), or psychopathology in either sample, meaning that criminally active participants may have been included in the normative sample, as well as those with comorbid psychopathology in either group. Despite substantial efforts, this study was unable to recruit more participants and the sample size was low. The inclusion of sex offenders may have 
introduced problematic confounding variables that this study did not account for, thereby making comparisons with the rest of the offender group and the normative sample difficult. For example, studies of sex offenders show that when compared to the general population, they are more likely to have an insecure attachment style, significant problems trusting intimate partners, leading to unstable adult romantic relationships and a greater propensity for aggression (Grady, Swett, \& Shields, 2016; Lyn \& Burton, 2005).

The demographic imbalance across the two samples presented additional difficulty when interpreting the findings. First, a majority male offender sample meant that female offender experiences were under-represented. Research has shown that males are more likely to engage in criminality compared to females (Farrington \& Painter, 2004). This finding was partially supported by the normative group regression, although the non-significant finding in the offender group may be attributed towards the gender imbalance of that sample. Yet as women make up only one tenth of all offenders supervised in the community by the NPS (Ministry of Justice, 2016), the final sample was a representative gender ratio of male-tofemale offenders currently supervised by the NPS. Second, although gender was controlled for in the study, the gender imbalance between the offender and normative samples makes it difficult to directly compare the two groups, particularly as research indicates that some risk factors for offending are gender-specific. For example, socioeconomic factors, such as low family income, are more relevant for female than male offenders (Farrington \& Painter, 2004). Future full-scale studies would benefit from comparing samples matched for gender and criminal background, screening for psychopathology, and by excluding sex offenders in the high-risk group and those with any offending history in the normative sample.

The relatively low proportion of variance captured in the study would suggest that parentification, avoidant attachment and emotional resilience are not useful predictors of 
antisocial behaviour. Other factors studied elsewhere, including the number of adverse childhood experiences, impulsivity, deviant peers and social deprivation (Duke et al., 2010; Lösel \& Farrington, 2012; Reavis et al., 2013) may therefore provide more predictive utility for antisocial behaviour across offending and normative populations.

\section{Applied value: Practice implications}

This pilot study's findings emphasise the influence of attachment anxiety on antisocial conduct, and the role this may play in offender therapy. Given the link between dysfunctional attachment and antisociality, practitioners have sought to bring attachment theory into the fore of forensic risk assessment and offender treatment due to its strength of successfully facilitating offenders' self-reflection, emotional recognition and behavioural management (Ansbro, 2008; Forbes \& Reilly, 2011). Although evidence from previous studies indicates that the dominant cognitive behavioural approach of working with offenders offers mixed results (e.g., Harper \& Chitty, 2005), currently, there is little in the way of specific attachment-based interventions widely available to all practitioners working in offender rehabilitation (Forbes \& Reilly, 2011). In addition, existing risk assessments could provide a fuller exploration of attachment issues, due to strong links between disrupted attachment and offending behaviour in the literature (e.g. Groh et al., 2017; Hoeve et al., 2009, 2012; Savage, 2014). The Offender Assessment System (OASys) provides an evaluation of an offender's areas of risk and need in various life domains, of which attachment forms only a single item that enquires about 'experiences of childhood' (Moore, 2015). Thus, if these pilot findings were replicated in full-scale studies, they would indicate a need to incorporate a more thorough assessment of attachment within offender risk assessment and management. 
Outside of intervention programmes, an awareness of attachment histories could help explain negative reactions of offenders within some relational contexts (Ansbro, 2018). Incorporating discussions of the offender's life history within existing risk assessment processes could help encourage offenders to identify the attachment deficits that partially contributed towards their antisocial conduct. Equally, staff practice should ideally focus on building, maintaining and being receptive to healthy attachments with offenders (Judd \& Lewis, 2015), which itself could serve as a protective factor against further antisocial behaviour.

These findings can guide evidence-based interventions, in early childhood, to curb the development of antisocial behaviour and deter the onset of early and persistent criminality. For example, Blaustein and Kinniburgh, (2018) assert that teachers, once trained, are well positioned to identify signs of poor attachment (e.g. low mood, aggression, inability to manage negative emotions), thereby enabling vulnerable children to receive support at school during this stage. Primary interventions that aim to build children's emotional resilience, enhancing their skills in coping with negative emotions, could also prove to be effective in countering the negative implications of early adverse experiences, such as dysfunctional attachment (Iwaniec, Larkin \& Higgins, 2006). Ultimately, this study's findings boost the use of early attachment-based training programmes, which have proved to be effective in schools and with families/parents (Weihrauch, Schafer, \& Franz, 2014).

\section{Conclusion}

This pilot study is novel in its comparison of an offender group with a normative group to examine the influence of childhood parentification, on attachment deficits and emotional resilience on adulthood antisociality. Future full-scale studies should bear in mind the limitations of this study and explore these findings further, by making a distinction 
between adultification and "healthy parentification" using larger, more explicit and better matched samples. The finding that offenders reported significantly more attachment anxiety than the normative group highlights a potential focus for offender therapy and intervention to target antisocial conduct in forensic practice. To this end, it is noteworthy that Ansbro (2008, p. 242) states: “[A]n attachment framework ... offers us a way of understanding our offenders, reactivating their sense of being understood, and nurturing their understanding of themselves and others".

Endnote:

1. The NPS is a public domain of the Probation Service, responsible for supervising all offenders either deemed to pose a high risk of harm to others and/or those serving 12 months or more imprisonment for a specified, violent or sexual, offence.

2. MAPPA is a multi-disciplinary approach to managing the risk of particularly dangerous offenders or, in some cases, those subject to significant media attention. Professionals from a range of organisations, including the Police, Probation Service, mental health workers, substance misuse workers and accommodation providers, meet regularly to ensure risk is being effectively managed. 


\section{References}

Amat, S., Subhan, M., Jaafar, W. M. W., Mahmud, Z., \& Johari, K. S. K. (2014). Evaluation and psychometric status of the Brief Resilience Scale in a sample of Malaysian international students. Asian Social Science, 10, 240-245. doi:10.5539/ass.v10n18p240

Ansbro, M. (2008). Using attachment theory with offenders. Probation Journal, 55(3), 231244. doi: $10.1177 / 0264550508092812$

Ansbro, M. (2018). Integrating attachment theory into probation practice: A qualitative study. The British Journal of Social Work. doi: 10.1093/bjsw/bcx161

Arbona, C., \& Power, T. G. (2003). Parental attachment, self-esteem, and antisocial behaviours among African American, European American, and Mexican American adolescents. Journal of Counseling Psychology, 50, 40-51. doi: 10.1037/00220167.50 .1 .40

Armstrong, M. I., Birnie-Lefcovitch, S., \& Ungar, M. T. (2005). Pathways between social support, family well-being, quality of parenting, and child resilience: What we know. Journal of Child and Family Studies, 14, 269-281. doi: 10.1007/s10826-005-5054-4

Barnett, B., \& Parker, G. (1998). The parentified child: early competence or childhood deprivation? Child Psychology and Psychiatry Review, 3, 146-155. doi: $10.1111 / 1475-3588.00234$

Blaustein, M. E., \& Kinniburgh, K. M. (2018). Treating traumatic stress in children and adolescents: How to foster resilience through attachment, self-regulation, and competency. Guilford Publications. 
Boszormenyi-Nagy, I, \& Sparks, M. G. (1973). Invisible Loyalties. Maryland, Hagerstown: Harper and Row Publishers, Inc

Bowlby, J. (1969). Attachment. Attachment and loss: Vol. 1. Loss. New York: Basic Books.

Brennan, K. A., Clark, C. L., \& Shaver, P. R. (1998). Self-report measurement of adult attachment: An integrative overview. In J. A. Simpson \& W. S. Rholes (Eds.), Attachment theory and close relationships (pp. 46-76). New York: Guilford Press.

Brooks, M., \& Khan, R. (2015). Psychosocial influences that motivate young offenders to engage in a non-custodial community intervention. The Journal of Forensic Psychiatry \& Psychology, 26, 351-367. doi: 10.1080/14789949.2015.1013973

Campbell-Sills, L., Cohan, S. L., \& Stein, M. B. (2006). Relationship of resilience to personality, coping, and psychiatric symptoms in young adults. Behaviour, Research and Therapy, 44, 585-599. doi: 10.1016/j.brat.2005.05.001

Chase, N. D. (Ed.). (1999). Burdened children: Theory, research, and treatment of parentification. London: Sage Publications.

Duke, N. N., Pettingell, S. L., McMorris, B.J., \& Borowsky, I. W. (2010). Adolescent violence perpetration: associations with multiple types of adverse childhood experiences. Pediatrics, 125, 778-786. doi: 10.1542/peds.2009-0597.

Farrington, D. P. (1995). The development of offending and antisocial behaviour from childhood: Key findings from the Cambridge Study in Delinquent Development. Journal of Child Psychology and Psychiatry, 6(36), 929-964. doi: 10.1111/j.14697610.1995.tb01342.x 
Farrington, D. P., \& Painter, K. (2004). Gender differences in risk factors for offending. London: Home Office.

Fox, B. H., Perez, N., Cass, E., Baglivio, M. T., \& Epps, N. (2015). Trauma changes everything: Examining the relationship between adverse childhood experiences and serious, violent and chronic juvenile offenders. Child Abuse \& Neglect, 46, 163-173. doi: 10.1016/j.chiabu.2015.01.011

Fraley, R. C., Waller, N. G., \& Brennan, K. A. (2000). An item response theory analysis of self-report measures of adult attachment. Journal of Personality and Social Psychology, 78, 350. doi: 10.1037//0022-3514.78.2.350

Garber, B. D. (2011). Parental alienation and the dynamics of the enmeshed parent-child dyad: Adultification, parentification, and infantilization. Family Court Review, 49(2), 322-335. doi: 10.1111/j.1744-1617.2011.01374.x

Grady, M. D., Swett, L., \& Shields, J. J. (2016). The impact of a sex offender treatment programme on the attachment styles of incarcerated male sexual offenders. Journal of Sexual Aggression, 22(1), 123-136. doi: 10.1080/13552600.2014.894148

Groh, A. M., Roisman, G. I., van., M. H., Bakermans-Kranenburg, M. J., \& Fearon, R. (2012). The significance of insecure and disorganised attachment for children's internalising symptoms: A meta-analytic study. Child Development, 83, 591-610. doi: 10.1111/j.1467-8624.2011.01711.x

Groh, A. M., Fearon, R. M. P., van IJzendoorn, M. H., Bakermans-Kranenburg, M. J. \& Roisman, G. I. (2017). Attachment in the early life course: Meta-analytic evidence for its role in socioemotional development. Child Development Perspectives, 11, 70-76. doi: 10.1111/cdep.12213 
Hansen, A. L., Waage, L., Eid, J., Johnsen, B. H. \& Hart, S. (2011). The relationship between attachment, personality and antisocial tendencies in a prison sample: A pilot study. Scandinavian Journal of Psychology, 52, 268-276. doi:10.1111/j.14679450.2010.00864.x

Hoeve, M., Dubas, J. S., Eichelsheim, V. I., Van Der Laan, P. H., Smeenk, W., \& Gerris, J. R. (2009). The relationship between parenting and delinquency: A meta-analysis. Journal of Abnormal Child Psychology, 37, 749-775. doi: 10.1007/s10802-009-9310-

Hoeve, M., Stams, G. J. J., van der Put, C. E., Dubas, J. S., van der Laan, P. H., \& Gerris, J. R. (2012). A meta-analysis of attachment to parents and delinquency. Journal of Abnormal Child Psychology, 40, 771-785. doi: 10.1007/s10802-011-9608-1

Hollin, C. R. (1990). Cognitive-Behavioural Interventions with Young Offenders. Oxford: Pergamon Press.

Hooper, L. M. (2008). Defining and understanding parentification: Implications for all counselors. Alabama Counseling Association Journal, 34, 34-43.

Hooper, L. M., DeCoster, J., White, N., \& Voltz, M. L. (2011). Characterising the magnitude of the relation between self-reported childhood parentification and adult psychopathology: A meta-analysis. Journal of Clinical Psychology, 67, 1028-1043. doi: $10.1002 /$ jclp.20807

Hooper, L. M., Marotta, S. A., \& Lanthier, R. P. (2008). Predictors of growth and distress following childhood parentification: A retrospective exploratory study. Journal of Child and Family Studies, 17, 693-705. doi: 10.1007/s10826-007-9184-8 
Hooper, L. M., \& Wallace, S. A. (2010). Evaluating the Parentification Questionnaire: Psychometric properties and psychopathology correlates. Contemporary Family Therapy, 32, 52-68. doi: 10.1007/s10591-009-9103-9

Iwaniec, D., Larkin, E., \& Higgins, S. (2006). Research review: Risk and resilience in cases of emotional abuse. Child \& Family Social Work, 11(1), 73-82.

Jankowski, P. J., Hooper, L. M., Sandage, S. J., \& Hannah, N. J. (2013). Parentification and mental health symptoms: Mediator effects of perceived unfairness and differentiation of self. Journal of Family Therapy, 35, 43-65. doi:

Judd, P., \& Lewis, S. (2015). Working against the odds: How probation practitioners can support desistance in young adult offenders. European Journal of Probation, 7, 5875. doi: $10.1177 / 2066220315575672$

Jurkovic, G. J., \& Thirkield, A. (1998). Parentification questionnaire. Available from GJ Jurkovic, Department of Psychology, Georgia State University, University Plaza, Atlanta, GA, 30303.

Jurkovic, G.J., Morrell, R., \& Thirkield, A. (1999). Assessing childhood parentification: guidelines for researchers and practitioners. In Chase, N. (Ed.) Burdened children: Theory, research and treatment of parentification (pp. 92-113). London: Sage Publications.

Khan, R. \& Cooke, D. J. (2008). Risk factors for severe inter-sibling violence (SISV) with and without weapon use: A preliminary study of a youth forensic sample. Journal of Interpersonal Violence, 23(11), 1513-1530. doi: 10.1177/0886260508314312 
Leitch, L. (2017). Action steps using ACEs and trauma-informed care: A resilience model. Health \& Justice, 5, 1-10. doi: 10.1186/s40352-017-0050-5

Levenson, J. S., Willis, G. M., \& Vicencio, C. P. (2017). Obstacles to help-seeking for sexual offenders: implications for prevention of sexual abuse. Journal of Child Sexual Abuse, 26, 99-120. doi: 10.1080/10538712.2016.1276116

Lösel, F., \& Farrington, D. P. (2012). Direct protective and buffering protective factors in the development of youth violence. American Journal of Preventive Medicine, 43, S8S23. doi: 10.1016/j.amepre.2012.04.029

Lyn, T. S., \& Burton, D. L. (2005). Attachment, anger and anxiety of male sexual offenders. Journal of Sexual Aggression, 11(2), 127-137. 10.1080/13552600500063682

Marshall, W. L. (2010). The role of attachments, intimacy, and loneliness in the etiology and maintenance of sexual offending. Sexual and Relationship Therapy, 25, 73-85. doi: $10.1080 / 14681990903550191$

Masten, A. S., Best, K. M., \& Garmezy, N. (1990). Resilience and development: Contributions from the study of children who overcome adversity. Development and Psychopathology, 2, 425-444. doi: 10.1017/S0954579400005812

McKnight, L., \& Loper, A. B. (2002). The effect of risk and resilience factors on the prediction of delinquency in adolescent girls. School Psychology International, 23, 186-198. doi: 10/.1177/0143034302023002744

Ministry of Justice (2016). Statistics on Women and the Criminal Justice System 2015. London: Ministry of Justice. 
Moore, R. (2015). A compendium of research and analysis on the Offender Assessment System (OASys) 2009-2013. London: Ministry of Justice.

Nurwianti, F., Poerwandari, E. K., \& Ginanjar, A. S. (2018). The role of family strength on the relationship of parentification and delinquent behaviour in adolescents from poor families. In A. A. Ariyanto, H. Muluk, P. Newcombe, F.P. Piercy, E. K. Poerwandari, S. Hartati, \& R. Suradijono, (Eds.), Diversity in Unity: Perspectives from Psychology and Behavioural Sciences (pp-19-26). Taylor \& Francis Group, London.

Ogilvie, C. A., Newman, E., Todd, L., \& Peck, D. (2014). Attachment \& violent offending: A meta-analysis. Aggression and Violent Behavior, 19(4), 322-339. doi: 10.1016/j.avb.2014.04.007

Reavis, J. A., Looman, J., Franco, K. A., \& Rojas, B. (2013). Adverse childhood experiences and adult criminality: how long must we live before we possess our own lives? The Permanente Journal, 17, 44-48. doi: 10.7812/TPP/12-072

Savage, J. (2014). The association between attachment, parental bonds and physically aggressive and violent behaviour: A comprehensive review. Aggression and Violent Behaviour, 19, 164-178. doi: 10.1016/j.avb.2014.02.004

Sibley, C. G., Fischer, R., \& Liu, J. H. (2005). Reliability and validity of the revised experiences in close relationships (ECR-R) self-report measure of adult romantic attachment. Personality and Social Psychology Bulletin, 31(11), 1524-1536. doi: $10.1177 / 0146167205276865$

Sigre-Leirós, V., Carvalho, J., \& Nobre, P. J. (2016). Early parenting styles and sexual offending behaviour: A comparative study. International Journal of Law and Psychiatry, 46, 103-109. doi: 10.1016/j.ijlp.2016.02.042 
Smith, B. W., Dalen, J., Wiggins, K., Tooley, E., Christopher, P., \& Bernard, J. (2008). The brief resilience scale: assessing the ability to bounce back. International Journal of Behavioural Medicine, 15, 194-200. doi: 10.1080/10705500802222972

Van Loon, L., Van de Ven, M. O., Van Doesum, K., Hosman, C. M., \& Witteman, C. L. (2015). Parentification, stress, and problem behaviour of adolescents who have a parent with mental health problems. Family Process, 56, 1-13. doi: 10.1111/famp.12165

Wagnild, G. (2009). A review of the Resilience Scale. Journal of Nursing Measurement, 17, 105-113. doi: 10.1891/1061-3749.17.2.105

Weihrauch, L., Schafer, R., \& Franz, M. (2014). Long-term efficacy of an attachment-based parental training program for single mothers and their children: a randomized controlled trial. Journal of Public Health, 22, 139-153. doi: 10.1007/s10389-013$0605-4$

Zemel, O., Ronel, N., \& Einat, T. (2016). The impact of introspection and resilience on abstention and desistance from delinquent behaviour among adolescents at risk. European Journal of Criminology, 13, 111-128. doi: 10.1177/1477370815587770 
Table 1. Percentage of 10 Antisocial Behaviour Items Reported by the Offender $(N=66)$ and Normative $(N=71)$ Samples.

\begin{tabular}{|c|c|c|c|c|c|c|c|}
\hline & Antisocial Behaviour Items & $\begin{array}{l}\text { Offender } \\
\text { or } \\
\text { Normative }\end{array}$ & Never & Once & Sometimes & Often & Always \\
\hline \multirow[t]{2}{*}{1.} & Intentionally vandalised property & Offender & 40 & 12 & 26 & 17 & 6 \\
\hline & $\begin{array}{l}\text { (used permanent substances or } \\
\text { smashed/broke objects) }\end{array}$ & Normative & 75 & 17 & 6 & - & - \\
\hline \multirow[t]{2}{*}{2.} & Intentionally took item from a shop & Offender & 55 & 20 & 12 & 12 & 2 \\
\hline & without paying for it & Normative & 76 & 18 & 3 & 3 & - \\
\hline \multirow[t]{2}{*}{3.} & Broke into a vehicle & Offender & 70 & 9 & 15 & 5 & 2 \\
\hline & (fun or theft) & Normative & 96 & 3 & 1 & - & - \\
\hline \multirow[t]{2}{*}{4.} & Broke into another person's & Offender & 73 & 9 & 11 & 6 & 2 \\
\hline & home/property (fun or theft) & Normative & 99 & 1 & - & - & - \\
\hline \multirow[t]{2}{*}{5.} & Broke into another person's vehicle & Offender & 68 & 11 & 12 & 6 & 3 \\
\hline & (joyriding or theft) & Normative & 99 & 1 & - & - & - \\
\hline \multirow[t]{2}{*}{6.} & Consumed alcohol & Offender & 11 & 6 & 39 & 14 & 30 \\
\hline & (before 18 years) & Normative & 27 & 10 & 38 & 16 & 10 \\
\hline \multirow[t]{2}{*}{7.} & Took any illegal substances & Offender & 32 & 2 & 21 & 18 & 27 \\
\hline & & Normative & 49 & 17 & 20 & 10 & 4 \\
\hline \multirow[t]{2}{*}{8.} & Intentionally provoked physical fight & Offender & 41 & 5 & 26 & 20 & 9 \\
\hline & with another person & Normative & 72 & 16 & 13 & - & - \\
\hline \multirow[t]{2}{*}{9.} & Physically abused another person & Offender & 91 & 6 & 2 & 2 & - \\
\hline & $\begin{array}{l}\text { (financial gain, skin colour or } \\
\text { religious beliefs) }\end{array}$ & Normative & 96 & 3 & 2 & - & - \\
\hline \multirow[t]{2}{*}{10} & Intentionally gone out with weapon & Offender & 68 & 20 & 8 & 3 & 1 \\
\hline & (intending to harm someone) & Normative & 96 & 4 & - & - & - \\
\hline
\end{tabular}

*Percentages may not total $100 \%$ as all figures are rounded. 
Table 2. Means, Standard Deviations, Minimum and Maximum Values for Offender and Normative data.

\begin{tabular}{|c|c|c|c|c|c|c|c|c|c|}
\hline & \multicolumn{4}{|c|}{ Offender $(N=66)$} & \multicolumn{4}{|c|}{ Normative $(N=71)$} & \multirow[b]{2}{*}{$p$} \\
\hline & $M$ & $S D$ & Min. & Max. & $M$ & $S D$ & Min. & Max. & \\
\hline Anxious attachment & 3.37 & 1.41 & 1.00 & 6.17 & 2.64 & 5.83 & 1.00 & 5.83 & .001 \\
\hline Avoidant attachment & 4.22 & 0.91 & 1.00 & 5.83 & 4.37 & 0.77 & 1.67 & 6.89 & .282 \\
\hline Parentification & 1.43 & 0.15 & 1.18 & 1.84 & 1.39 & 0.17 & 1.09 & 1.80 & .223 \\
\hline Emotional resilience & 2.93 & 1.39 & 1.00 & 5.00 & 3.26 & 0.76 & 1.33 & 5.00 & .093 \\
\hline Antisocial behaviour & 20.74 & 7.82 & 10.00 & 43.00 & 14.04 & 3.38 & 10.00 & 24.00 & $<.001$ \\
\hline
\end{tabular}

Note. $p$ column indicates whether there are significant differences between the offender and normative groups. 
Table 3. Correlations between Variables for Offender $(N=66$; above the diagonal $)$ and Normative (N=71; below the diagonal) Data.

\begin{tabular}{lccccc}
\hline & 1 & 2 & 3 & 4 & 5 \\
\hline 1. Anxious attachment & - & -.33 & .22 & $-.40^{* *}$ & -.01 \\
2. Avoidant attachment & -.06 & - & .07 & .03 & -.04 \\
3. Parentification & $.32 * *$ & -.21 & - & -.13 & .06 \\
4. Emotional resilience & $-.26^{*}$ & .03 & $-.23 *$ & - & .02 \\
5. Antisocial behaviour & & & & & \\
\end{tabular}

Note. $* p<.05, * * p<.01, * * * p<.001$. 
Table 4. Summary of Hierarchical Regression Analysis for Offender $(N=66)$ and Normative $(N=71)$ Samples with Antisocial Behaviour as the Criterion.

\begin{tabular}{|c|c|c|c|c|c|c|c|c|c|c|}
\hline \multirow[b]{2}{*}{ Variable } & \multicolumn{5}{|c|}{ Offender sample } & \multicolumn{5}{|c|}{ Normative sample } \\
\hline & $B$ & SE & $\beta$ & $\operatorname{Adj} . R^{2}$ & $\Delta R^{2}$ & $B$ & SE & $\beta$ & Adj. $R^{2}$ & $\Delta R^{2}$ \\
\hline Step 1 & & & & .27 & $.29 * * *$ & & & & .05 & .08 \\
\hline Gender & 2.56 & 3.50 & .08 & & & -2.24 & .95 & $-.30 *$ & & \\
\hline Age & -.30 & .06 & $-.52 * * *$ & & & -.01 & .03 & -.05 & & \\
\hline Step 2 & & & & .23 & .08 & & & & .19 & $.18^{*}$ \\
\hline Gender & 2.55 & 3.74 & .08 & & & -1.76 & .91 & -.23 & & \\
\hline Age & -.30 & .06 & $-.53 * * *$ & & & -.04 & .03 & -.15 & & \\
\hline Anxious attachment & .22 & .69 & .04 & & & .64 & .37 & .21 & & \\
\hline Avoidant attachment & -.64 & 1.08 & -.07 & & & .00 & .51 & .00 & & \\
\hline Parentification & 1.01 & 1.02 & .02 & & & -.75 & 1.58 & -.04 & & \\
\hline Emotional resilience & .06 & .69 & .01 & & & 2.06 & .60 & $.43 * *$ & & \\
\hline
\end{tabular}

Note. Gender coded: $0=$ male, $1=$ female. $\Delta R^{2}=R^{2}$ change. ${ }^{*} p<.05, * * p<.01, * * * p<.001$. 